\title{
O novo espírito do capitalismo e a construção da universidade empreendedora no contexto brasileiro
}

\author{
The new spirit of capitalism and the construction of the \\ entrepreneurial university the Brazilian context
}

El nuevo espíritu del capitalismo y la construcción de la
universidad empreendedora en el contexto brasilero

Recebido em 05-11-2019

Modificado em 30-03-2020

Aceito para publicação em 20-04-2020

\begin{abstract}
Alice Hübner Franz
ORCID: 0000-0001-8475-2178

Graduada em administração (UCPel); Mestra em desenvolvimento territorial e sistemas agroindustriais; Doutoranda em administração (UFSC). Bolsista CAPES; Pesquisadora do Observatório da Realidade Organizacional - SC (UFSC). E-mail: alicefranz1@gmail.com
\end{abstract}

\section{Gabriel Bandeira Coelho \\ ORCID: 0000-0003-3579-582X}

Graduado em ciências sociais (UFPel); Mestre em sociologia (UFPel); Doutor em sociologia (UFRGS). Pesquisador do grupo Tecnologia, Meio Ambiente e Sociedade (TEMAS/UFRGS). E-mail: gabrielbandeiracoelho@yahoo.com.br

\section{Resumo}

O presente artigo se propõe a analisar, à luz da teoria do novo espírito do capitalismo, dos sociólogos Luc Boltanski e Éve Chiapello, o documento "Universidades Empreendedoras", o qual foi elaborado em 2016 pela Confederação Brasileira de Empresas Júnior em conjunto com outras instituições representativas. Este documento aborda o índice das universidades mais empreendedoras do Brasil. Logo, a questão norteadora deste artigo é: o discurso presente no documento "Universidades Empreendedoras" reflete a lógica social inspirada pelo novo espírito do capitalismo? Mais especificamente, se intentou identificar, no documento proposto para a análise, argumentos, valores, justificações e características que possam remeter ao aparato ideológico típico do novo espírito do capitalismo. Como conclusão, pode-se dizer que o discurso presente no documento analisado apresenta argumentos que refletem, ao mesmo tempo em que fortalecem, os novos imperativos advindos da instauração de um novo espírito do capitalismo, conforme proposto por Boltanski e Chiapello.

Palavras-chave: Educação Superior; Empreendedorismo; Universidade empreendedora; Novo espírito; Capitalismo. 


\section{Introdução}

Flexibilidade, inovação, empreendedorismo, adaptação, autonomia e mobilidade são termos que têm sido amplamente disseminados no espaço social, tornando-se cada vez mais comuns na atualidade, figurando tanto em estudos e em pesquisas no cenário intelectual nacional e internacional, quanto no ambiente empresarial.

A ampla disseminação desses termos, assim como de práticas a eles ligadas se dá, de acordo com Boltanski e Chiapello (2009), em virtude da dinâmica do sistema capitalista que, para manter a sua existência, sua expansão e a adesão de diferentes atores necessita de um amplo aparato moral, normativo e justificativo, os quais acabam por refletir a essência do espírito do capitalismo. O espírito que rege atualmente o capitalismo, o "novo espírito do capitalismo", conforme defendem Boltanski e Chiapello (2009), edificado a partir dos anos 1970, em respostas às críticas advindas, sobretudo, dos movimentos de maio de 1968, está ancorado em justificativas que prezam por um modo de vida que envolve, principalmente, aspectos voltados à mobilidade, flexibilidade e adaptabilidade.

Dado que esse espírito se caracteriza como uma ideologia dominante, ele acaba perpassando os mais diferentes aspectos da vida, refletindo em novas configurações no tecido social, cujos efeitos podem ser observados na dinâmica das instituições familiares - as quais tornaram-se mais frágeis e móveis -, na organização das empresas - que agora prezam pela flexibilidade, inovatividade e mobilidade -, além da organização do próprio trabalho - que também passa a flexibilizar-se a partir da terceirização, dos contratos temporários, da intensificação do trabalho autônomo, entre outros (Boltanski; Chiapello, 2009).

Tendo em vista que o cabedal teórico desses autores tem sido utilizado para observar os mais diferentes fenômenos sociais (Maia; Germano, 2014; Casaqui, 2015; Petry, 2017; Gonçalo, 2015), neste trabalho, em específico, interessa-nos identificar se a reestruturação do capitalismo, vislumbrada a partir da emergência de um novo espírito, tem afetado também as construções discursivas no âmbito da educação e, mais especificamente, da educação superior. Para tanto, parte-se do estudo de um discurso o qual tem se intensificado nos últimos anos no contexto social brasileiro, a saber: a universidade empreendedora.

Portanto, o presente artigo se propõe a analisar, à luz da teoria do novo espírito do capitalismo, dos sociólogos Luc Boltanski e Éve Chiapello, o documento "Universidades Empreendedoras" (Brasil Júnior et al, 2016), o qual foi elaborado em 2016 pela Confederação Brasileira de Empresas Júnior em conjunto com outras instituições representativas. Tal documento aborda o índice das universidades mais empreendedoras do Brasil. Logo, a 
questão norteadora deste artigo está pautada em: o discurso presente no documento "Universidades Empreendedoras" reflete a lógica social característica do novo espírito do capitalismo?

Mais especificamente, se intenta identificar no documento proposto para a análise os argumentos e valores, bem como as justificações e características que possam remeter ao aparato ideológico típico do novo espírito do capitalismo.

Justifica-se o interesse em lançar os olhares às universidades empreendedoras, a partir do documento acima mencionado, pois se acredita que o mesmo fornece um quadro analítico conceitual recente, o qual trabalha o conceito de universidade empreendedora voltado para o contexto brasileiro e para as suas universidades.

Cabe destacar ainda que este artigo se utiliza da análise de discurso, cujo intuito é analisar e interpretar os elementos discursivos (qualitativos) que subjazem os discursos do documento ora analisado. Portanto, e justificando a escolha desse recurso metodológico, a análise de discurso tem como enfoque central, diferentemente da análise de conteúdo, a articulação entre o linguístico e o social, "buscando [conhecer] as relações que vinculam a linguagem à ideologia" (Brandão, 2004:09).

\section{O novo espírito do capitalismo: possibilidades para compreender a universidade empreendedora}

As mudanças de caráter ideológico ${ }^{1}$, as quais têm acompanhado as recentes transformações ocorridas no capitalismo, constituem o cerne do desenvolvimento do livro $O$ novo espírito do capitalismo (2009), escrito por Luc Boltanski e Éve Chiapello. Tendo em vista a busca pelo entendimento de tais mudanças, os autores desenvolvem uma articulação, até então inédita, entre os conceitos de "capitalismo", "espírito do capitalismo" e "crítica". A partir da identificação de tais conceitos-chave, torna-se igualmente relevante elucidar a forma como cada um deles é compreendido pelos autores, bem como narrar o emaranhado teórico proposto por eles com o intuito de dar conta das modificações ideológicas relacionadas ao desenvolvimento capitalista das últimas décadas.

Boltanski e Chiapello (2009:35) entendem o capitalismo como sendo "a exigência de acumulação ilimitada do capital por meios formalmente pacíficos". Trata-se, portanto, da necessidade de incorporar constantemente o capital junto à dinâmica econômica, com o

\footnotetext{
${ }^{1}$ Boltanski e Chiapello entendem ideologia, de acordo com Dumont, como um "conjunto de crenças compartilhadas, inscritas em instituições, implicadas em ações e, portanto, ancoradas na realidade" (2009:33).
} 
propósito de gerar lucros para que, então, ele possa ser novamente reinvestido. Esta é a essência do capitalismo, aquilo que proporciona a sua dinâmica e a sua força transformadora (Boltanski; Chiapello, 2009).

Para que essa dinâmica do capitalismo possa obter êxito, é imprescindível a colaboração ativa e voluntária de diferentes atores, os quais possuem papeis distintos no processo de acumulação do capital. Dentre esses atores, se encontram os capitalistas, aqueles que são responsáveis pela acumulação de capital e, consequentemente, pelo seu crescimento, além dos assalariados, caracterizados por não possuírem os meios de produção, tendo que vender sua força de trabalho para adquirirem seus rendimentos para subsistência (Boltanski; Chiapello, 2009).

Para que tais atores, protagonistas desse sistema, mantenham-se engajados e motivados a atuarem nessa dinâmica capitalista, torna-se necessária a existência de justificações, pois, somente fatores monetários e/ou formas coercitivas não asseguram esse empenho, principalmente quando se trata daqueles atores cuja possibilidade de lucro é mínima (Boltanski; Chiapello, 2009). Essas justificações, conforme discorrem os autores, relacionamse tanto a garantias individuais (motivações pessoais que servem de incentivo para que o indivíduo se empenhe na empresa capitalista), assim como garantias mais gerais, relacionadas essencialmente ao bem comum. Nesse sentido, por trás da justificação, há uma legitimidade quase que natural, a qual mantém essa estrutura, essa relação entre patrão e empregado.

Logo, evidencia-se que o capitalismo carece de um conjunto de crenças e de valores que o justifique de tal modo que seja capaz de convencer e de manter o estímulo e o engajamento dos diferentes atores indispensáveis para a sua manutenção. Portanto, é nesse contexto que emerge, segundo Boltanski e Chiapello (2009:39;42), o "espírito do capitalismo", conceito que representa a "ideologia que justifica o engajamento no capitalismo", isto é, "o conjunto de crenças associadas à ordem capitalista que contribuem para justificar e sustentar essa ordem, legitimando os modos de ação e as disposições coerentes com ela". Ainda conforme destacam os autores:

Essas justificações, sejam elas gerais ou práticas, locais ou globais, expressas em termos de virtudes ou em termos de justiça, dão respaldo ao cumprimento de tarefas mais ou menos penosas e, de modo mais geral, à adesão a um estilo de vida, em sentido favorável à ordem capitalista (Boltanski; Chiapello, 2009:42).

Em síntese, o capitalismo, enquanto instituição social e não fugindo à regra de outros sistemas de crenças e ideais, deve desenvolver justificações que sejam atraentes o suficiente para que os indivíduos se mantenham comprometidos no processo de acumulação instituído 
por ele, proporcionando-lhes, ao mesmo tempo, garantias de segurança, além de indicar razões que sejam moralmente aceitas para permanecerem atuantes nesse processo. Infere-se, ante a esse argumento, que existe um imaginário - nos termos de Harari (2017) - que legitima, justifica e cria uma moral, uma crença coletiva e intersubjetiva que institucionaliza e até mesmo naturaliza a ordem capitalista.

Frente a construção deste cenário, torna-se essencial trazer à tona o conceito de "cidades" (cités), entendidas como pontos de apoio normativos, diretamente voltados para o bem comum, dos quais o capitalismo se utiliza para a construção das suas justificações (Boltanski; Chiapello, 2009). São essas cidades que tornam viáveis a identificação dos diferentes regimes de justificação presentes no espírito do capitalismo e, são a estas cidades, que o capitalismo faz referência para moldar o seu espírito. Esta é, portanto, a essência do espírito do capitalismo, o qual se modifica com o passar do tempo conforme as expectativas existentes dos indivíduos que ele busca mobilizar, conforme as esperanças com as quais eles cresceram e a partir da configuração que a acumulação assume nas diferentes épocas (Boltanski; Chiapello, 2009).

Ademais, tais regimes de justificação se tornam importantes instrumentos utilizados pelo capitalismo para criar uma força de resistência perante as críticas anticapitalistas ${ }^{2}$ que emergem com o decorrer dos anos. O espírito do capitalismo não se modifica por acaso ou por influência das mudanças econômicas de caráter estruturais que acabam por afetar o próprio capitalismo, mas sim, em função das críticas direcionadas ao capitalismo que, conforme apontam Boltanski e Chiapello (2009), funcionam como uma mola propulsora para essas modificações.

Dito isso, infere-se que a crítica à ordem capitalista influencia diretamente no espírito do capitalismo, causando impactos significativos sobre este último. Em geral, quando o capitalismo é levado a responder as críticas a ele destinadas, ele incorpora, em parte, os valores pelos quais é criticado, passando a alterar o modo pelo qual atua, modificando, consequentemente, o seu espírito (Boltanski; Chiapello, 2009). A partir do momento em que o capitalismo internaliza os valores exaltados pela crítica, ele acaba por apaziguá-la, além de

\footnotetext{
${ }^{2}$ Embora o capitalismo não possa prescindir de uma orientação para o bem comum, da qual seja possível extrair motivos de engajamento, sua indiferença normativa não permite que o espírito do capitalismo seja gerado apenas a partir de seus próprios recursos; assim, ele precisa de seus inimigos daqueles que ele indigna, daqueles que se lhe opõem, para encontrar os pontos de apoio morais que lhe faltam e incorporar dispositivos de justiça que, sem isso, ele não teria nenhuma razão para considerar pertinentes (Boltanski; Chiapello, 2009:61).
} 
torná-lo novamente legítimo aos olhos daqueles de quem ele necessita para manter-se. Nesse sentido,

\begin{abstract}
O efeito dinâmico da crítica sobre o espírito do capitalismo passa aí pelo reforço das justificações e dos dispositivos associados que, sem pôr em xeque o próprio princípio de acumulação e a exigência de lucro, dá parcialmente satisfação à crítica e integra ao capitalismo injunções correspondentes às questões que mais preocupavam seus detratores (Boltanski; Chiapello, 2009:63).
\end{abstract}

Boltanski e Chiapello (2009:49) apontam para a existência de três diferentes estados históricos do espírito do capitalismo, além da "reconstituição arqueológica do éthos que inspirou o capitalismo original", proposta por Weber (2004) em A ética protestante e o espírito do capitalismo. O primeiro espírito identificado pelos autores originou-se no século XIX e estava centrado no detalhamento dos valores da burguesia, bem como na figura dinamizadora do burguês empreendedor. Neste espírito em específico, o capitalismo tinha como foco a liberdade, sobretudo espacial e/ou geográfica, assegurada pelo desenvolvimento dos meios comunicacionais e pelo trabalho assalariado (Boltanski; Chiapello, 2009).

Esse primeiro espírito prevaleceu até os anos de 1930, quando veio à tona um novo segundo espírito, o qual tinha a burocracia como modelo de gestão ideal e estava amplamente voltado para o desenvolvimento da organização e da grande empresa industrial. Esta última representada pela imagem heroica do diretor, aquele envolto de desejos de ampliar o tamanho da empresa a qual dirige, através do desenvolvimento de uma produção em larga escala e padronizada, a partir da utilização da racionalização do trabalho e de técnicas de marketing (Boltanski; Chiapello, 2009).

O segundo espírito, que foi acima descrito, já não é mais amplamente aceito e disseminado, cedendo espaço para o surgimento de uma nova configuração ideológica, ou seja, de um "novo" espírito do capitalismo. Portanto, "o terceiro espírito" que vem se configurando a partir dos anos de 1970, apoiado, principalmente, no modelo analítico da "cidade por projetos", na qual esse novo espírito angaria suas justificações (Boltanski; Chiapello, 2009).

A cidade por projetos faz alusão a um novo imperativo que se constrói em torno de um mundo mais flexível, composto por uma gama de projetos dirigidos por pessoas autônomas. Conforme argumentam Boltanski e Chiapello (2009), a forma a qual este novo espírito do capitalismo encontra para representar o mundo está centrada no modelo de "rede". Tal modelo faz referência às estruturas pouco ou nada hierarquizadas, flexíveis e isentas de limitações. A vida social passa, então, a ser representada por "uma multiplicidade de encontros e conexões temporárias, mas reativáveis, em grupos diversos, realizados em 
distâncias sociais, profissionais, geográficas e culturais eventualmente muito grandes" (Boltanski; Chiapello, 2009:135). Nesse contexto, o projeto emerge como um pretexto e como uma forma de oportunizar a conexão, pois, de acordo com Boltanski e Chiapello (2009:135) ele se constitui em "um bolsão de acumulação temporário que, sendo criador de valor, dá fundamento à exigência de ampliar a rede, favorecendo conexões”.

Diante das reivindicações advindas dos grandes representantes capitalistas (como os líderes das megas corporações internacionais que dominam o mercado global) por mais autonomia, justiça social e liberdade, a sua nova faceta - especialmente a atual ideia de empreendedorismo - exalta modelos de gestão menos hierarquizados, com empresas mais flexíveis e inventivas, menos controladoras, mais enxutas, com modos de organização mais pessoais e humanos, com o trabalho organizado por equipes, onde nada é imposto, pois todos aderem ao projeto (Boltanski; Chiapello, 2009). Além disso, esse novo espírito floresce diante das críticas voltadas à mecanização do mundo e a natureza intolerável das formas de opressão. É através do desenvolvimento do projeto voltado a autorrealização, que conjuga tanto a valorização do desempenho individual e a flexibilidade, quanto a valorização da interação social através da formação de redes, que esse novo espírito do capitalismo visa garantir o engajamento dos atores a ele indispensáveis, bem como a sua revalorização e a sua permanência (Boltanski; Chiapello, 2009).

Portanto, na cidade por projetos, a grandeza das pessoas e das coisas são medidas pela noção de atividade, de envolvimento em projetos, de ampliação da rede e de proliferação dos elos (Boltanski; Chiapello, 2009). Nesse sentido, segundo afirmam Boltanski e Chiapello (2009), os humanos imersos nesse mundo conexionista, que incorporam os valores típicos dessa nova ordem emergente, são qualificados como entusiastas, envolvidos, flexíveis, adaptáveis, polivalentes, empregáveis, autônomos, tolerantes, líderes de si mesmos, inovadores, capazes de se engajar e de engajar os demais e dispostos a assumir riscos. E é aqui que identificamos as principais características da noção de empreendedorismo, este que, por seu turno, emerge e se confunde com o próprio desenvolvimento do terceiro espírito do capitalismo.

Com efeito, o terceiro/novo espírito do capitalismo, ao penetrar diversos âmbitos do tecido social, como a família, a economia, o direito, a política e a educação, por exemplo, não ficou alheio ao ensino superior, tanto no Brasil, como alhures. Queremos dizer com tal argumento que a lógica (econômica e social) operada por esse novo espírito adentrou à esfera da educação nas universidades, fazendo-as incorporá-lo, através de seus mecanismos de justificação, cujo objetivo é fazer dessas universidades um locus empreendedor, onde o 
modelo empresarial é incorporado como padrão de gestão, inovação e produção, tal como a prerrogativa presente na definição das "cidades por projetos". É diante desses argumentos que entendemos o discurso acerca da universidade empreendedora como um discurso que corresponde ao espírito do capitalismo em voga.

\section{Universidade empreendedora e a lógica do novo espírito do capitalismo}

Tendo em vista que se pretende olhar para a universidade empreendedora utilizando-se a lente da teoria proposta por Boltanski e Chiapello (2009), torna-se igualmente relevante expor, através de uma rápida exposição, alguns conceitos e características que visam resgatar o que a literatura entende como sendo uma universidade empreendedora, para, então, prosseguir com a análise que se propôs.

O pressuposto inicial que objetiva sintetizar à crescente disseminação do discurso da universidade empreendedora, está relacionado à crença de que tanto as universidades quanto outras instituições produtoras de conhecimento estão tornando-se cada vez mais centrais nos sistemas de inovação de diferentes países devido ao reconhecimento do potencial exercido por elas na geração de crescimento econômico (Etzkowitz, 2004).

Clark (1998), um dos primeiros autores a falar de universidade empreendedora, a define como sendo aquela que busca inovar ativamente em sua forma de atuação, que busca promover mudanças em sua arquitetura organizacional observando um futuro promissor e que procura se tornar uma universidade "stand up", configurando-se como um importante ator. Para o autor, esse processo de construção de uma universidade empreendedora exige esforços voluntários que demandarão muita atividade e energia, além da existência de riscos por serem adotadas novas práticas com resultados ainda desconhecidos (Clark, 1998).

Corroborando o argumento anterior, Etzkowitz et al (2000) e Etzkowitz (2003) destacam que as universidades empreendedoras são aquelas que englobam em sua missão, além do ensino e da pesquisa, o desenvolvimento econômico, e passam a atuar em prol deste. Segundo o autor, o movimento que indica a emergência deste conceito está relacionado com o que ele denomina de "segunda revolução acadêmica"3, a qual permitiu que as universidades passassem a ter, também, a missão de apoio ao desenvolvimento econômico e social. Assim, é com a incorporação desta missão que surge a noção de "universidade empreendedora", intimamente relacionada com a capacidade das universidades transformarem o conhecimento

\footnotetext{
${ }^{3}$ De acordo com o autor, esta segunda revolução ocorre no âmbito universitário entre o final do século XX e início do século XXI (Etzkowitz, 2004).
} 
produzido através de pesquisas em atividade econômica, processo este denominado de “capitalização do conhecimento"4 (Etzkowitz, 2004).

O que se observa, a partir de então, de acordo com o autor, é uma mudança de atitude, tanto do corpo docente como do discente, no que tange aos resultados produzidos através da realização de pesquisas, bem como no desenvolvimento de diferentes mecanismos organizacionais que visam a transferência do conhecimento e da tecnologia gerados nas universidades (Etzkowitz, 2002). Para tanto, o autor afirma ainda que a universidade deve definir uma direção estratégica, com a formulação de objetivos claros e com a transformação do conhecimento produzido em valor econômico e social, além de acreditar que a universidade é um locus apropriado para a criação de inovações, tendo em vista a concentração de conhecimento e de capital intelectual existente. Ademais, a noção de universidade empreendedora, para este autor, está intimamente relacionada ao modelo hélice tríplice, modelo este que defende que universidade, empresa e governo devem prezar por uma interação conjunta e dinâmica, a fim de melhorar as condições da inovação em uma sociedade que valoriza, cada vez mais, o conhecimento (Etzkowitz; Mello, 2004). Segundo Etzkowitz et al (2000), para que estas instituições se tornem efetivas universidades empreendedoras, elas devem incorporar os mecanismos de desenvolvimento e as estruturas emergentes abaixo descritas:

a) Transformação interna: as tradicionais tarefas da universidade são revistas e ampliadas conforme as novas demandas;

b) Impacto trans-institucional: indústria e governo desenvolvem cada vez mais capacidades intermediárias semelhantes, emergindo um equilíbrio dessas esferas institucionais;

c) Processos de interface: a universidade empreendedora exige uma maior capacidade de inteligência, monitoramento e negociação com outras esferas institucionais, especialmente a indústria e o governo;

d) Efeitos recursivos: além de estabelecer vínculos com organizações existentes, a universidade empreendedora também desenvolve mecanismos que auxiliam na criação de novas empresas.

\footnotetext{
${ }^{4}$ Para Etzkowitz (1998), a capitalização do conhecimento emerge no momento em que o empreendedorismo acadêmico entra em cena manifestando-se como uma extensão das práticas de ensino, no amadurecimento de práticas de transferência tecnológica. Esta capitalização do conhecimento passa a ligar mais rigorosamente as universidades aos usuários de seus conhecimentos, configurando-a como um ator econômico por direito próprio.
} 
Ademais, Clark (1998) enumera cinco elementos necessários para a estruturação de uma universidade empreendedora. O primeiro deles é a construção de um núcleo de direção reforçado que está diretamente relacionado com a capacidade gerencial da universidade que deve agir ativamente às necessidades de mudança. O segundo elemento é uma periferia de desenvolvimento expandida que está ligada ao desenvolvimento de unidades que buscam relacionamentos com organizações externas à universidade, como os escritórios de divulgação e os centros de pesquisas interdisciplinares. Uma base de financiamento diversificada se constitui no terceiro elemento e está relacionado ao fato de que as universidades não podem depender exclusivamente de uma fonte de pesquisa, devendo buscar diversificar suas fontes financiadoras. O quarto ponto diz respeito ao desenvolvimento de um coração acadêmico estimulado que envolve a aceitação, por parte de departamentos centrais da universidade, em alterarem suas posturas em prol da inovação e das novas configurações organizacionais. $\mathrm{O}$ quinto e último elemento diz respeito a uma cultura empreendedora integrada ligada à determinada mudança disseminada ao longo do tempo em todos os níveis organizacionais da universidade.

Especificamente no contexto brasileiro, no ano de 2016, foi lançado pela Confederação de Empresas Juniors (Brasil Junior), com o apoio de outras organizações ${ }^{5}$, um índice inédito que elenca as principais universidades empreendedoras brasileiras, construído com os objetivos de: dar novos estímulos à educação superior, consolidar as transformações ocorridas no âmbito das universidades brasileiras e evidenciar o rumo que tais transformações estão tomando (Brasil Junior et al, 2016). Nesse índice ${ }^{6}$, universidade empreendedora é definida como "a comunidade acadêmica inserida em um ecossistema favorável, que desenvolve a sociedade por meio de práticas inovadoras" (Brasil Junior et al, 2016:31). Os criadores do índice entendem, portanto:

[...] que as instituições são compostas especialmente por pessoas que a ela se integram, sendo a Universidade Empreendedora a comunidade acadêmica, medida por meio da sua cultura empreendedora. Ela deve estar inserida em um ecossistema favorável que significa ter: infraestrutura, capital financeiro e internacionalização de boas práticas e projetos (Brasil Junior et al, 2016:33).

Ao traçar como objetivo principal "dar novos estímulos à educação superior”, o documento "Universidades Empreendedoras" se configura como uma tentativa de promover

\footnotetext{
${ }^{5}$ Rede CsF, Aiesec, Brasa e Enactus.

${ }^{6}$ Cabe salientar que este índice foi construído a partir de uma pesquisa realizada com a comunidade acadêmica das universidades escolhidas para participarem do ranking. Portanto, a construção deste índice reflete o pensamento de sua comunidade acadêmica.
} 
um ideal de universidade ao trazer, em seu conteúdo, "diretrizes pragmáticas e casos de sucesso nacionais e internacionais que podem ser aplicados diretamente em nossas universidades, seja por meio do protagonismo acadêmico, de políticas públicas ou da sociedade de forma geral" (Brasil Junior et al, 2016:25). Por ser um documento voltado para as universidades e à sua comunidade acadêmica em geral, ele possui um apelo moral e normativo, capaz de exercer forte influência no ambiente acadêmico, ao defender a aplicabilidade de um projeto de universidade em específico, ou seja, por difundir, em seu conteúdo, práticas, estruturas e ideias organizacionais direcionadas a um tipo-ideal de universidade que assume o adjetivo de "empreendedora".

Os autores do documento defendem que uma universidade empreendedora se constitui na sua "comunidade acadêmica, inserida num ecossistema favorável, que desenvolve a sociedade por meio de práticas inovadoras" (Brasil Junior et al, 2016:44). Assim, a noção de ecossistema, apresentada no conceito, liga-se à ideia de que, no ambiente universitário, existem pessoas que estão integradas e em constante interação, gerenciando os mais diferentes recursos disponíveis, nos mesmos moldes das redes de conexão das cidades por projetos do terceiro espírito do capitalismo. Isto significa dizer que a universidade empreendedora ou o “ecossistema favorável” a ela relacionado pode ser caracterizada por uma lógica projetista nos termos de Boltanski e Chiapello.

Nesse sentido, para que esse ecossistema se torne empreendedor e, consequentemente, favorável ao desenvolvimento da sociedade, algumas variáveis específicas devem ser potencializadas e estimuladas (Brasil Junior et al, 2016). Dito isso, entende-se que é somente através da criação de um ambiente ou de um "ecossistema" que priorize o empreendedorismo, que a universidade aderirá e estimulará práticas inovadoras, a fim de proporcionar o desenvolvimento da sociedade, por meio de suas justificações e das redes constituídas a partir da dinâmica de projetos do novo espírito do capitalismo.

Com efeito, tanto a defesa e o estímulo ao empreendedor e ao empreendedorismo, quanto a defesa de práticas inovadoras são elementos característicos e amplamente exaltados que atravessam o imaginário dessa nova configuração ideológica do capitalismo atual. Além disto, destacamos que o "desenvolvimento da sociedade" emerge como uma forma de justificação para facilitar a adoção e a reprodução de práticas que garantam a adesão e o engajamento dos indivíduos no novo espírito do capitalismo. Tal fato pode ser percebido em uma citação logo no prefácio do documento, escrito por Henry Etzkowitz: 
O objetivo é encorajar professores, estudantes e servidores a 'elevarem o seu jogo' em colocar o seu conhecimento em prática ao reconhecer realizações, incluindo formação e crescimento de startups, difusão da educação empreendedora em todo o espectro acadêmico, bem como participação e liderança em projetos locais e regionais para o desenvolvimento econômico e social (Etzkowitz, 2016:8).

Não obstante a isso, os autores do documento destacam ainda que "[...] a universidade empreendedora tem como principal cliente o estudante universitário e como cliente secundário a sociedade. Sendo também a função da universidade empreendedora sair dos seus muros e aplicar os conhecimentos adquiridos em prol da sociedade [...]" (Brasil Junior et al, 2016:33). Essa noção faz com que as universidades se assemelhem às empresas, transmitindo a ideia de que elas devem atuar conforme as demandas dos "clientes" estudantes, transformando-as em organizações prestadoras de serviços. Segundo Boltanski e Chiapello (2009), com a emergência do novo espírito do capitalismo, o cliente se configura no novo "patrão", tornando-se imprescindível para que as empresas estejam atentas às exigências de seus clientes e passem a atuar em prol da satisfação destes últimos. Tal lógica parece não se restringir apenas ao campo empresarial, sendo também utilizada, como acima descrito, nas construções discursivas orientadas à educação superior, como no caso do documento analisado, no qual o aluno transforma-se em cliente, o professor em uma espécie de vendedor e a universidade em um grande balcão de negócios.

Igualmente, é defendido, ainda no prefácio do documento, que, a partir da combinação entre pesquisa básica, ensino e inovação tecnológica, a universidade deixa de ser conhecida como uma "torre de marfim" e passa a ser reconhecida como empreendedora (Brasil Júnior et al, 2016), ou seja, passa a estar em consonância com os novos imperativos do novo espírito do capitalismo. A própria noção de "torre de marfim" remete a um conjunto de práticas antes aceitas e que hoje são amplamente criticadas, tal como uma instituição fechada, planificada, superespecializada e desconexa do mundo.

No que concerne à efetiva construção do índice das universidades mais empreendedoras do Brasil, os autores do documento mapearam algumas variáveis, as quais eles julgam essenciais para a criação de um ecossistema (um projeto) empreendedor no âmbito das universidades. Ademais, realizaram uma pesquisa junto a diversos estudantes universitários brasileiros, com o intuito de compreender a relevância dessas diferentes variáveis para construção de universidades mais empreendedoras, para, a partir disso, avaliarem as práticas de algumas das universidades brasileiras. 
Frente a isso, os autores do documento trazem uma imagem (figura 1) que reúne diferentes palavras, as quais expressam o que os respondentes da pesquisa entendem como sendo uma universidade empreendedora.

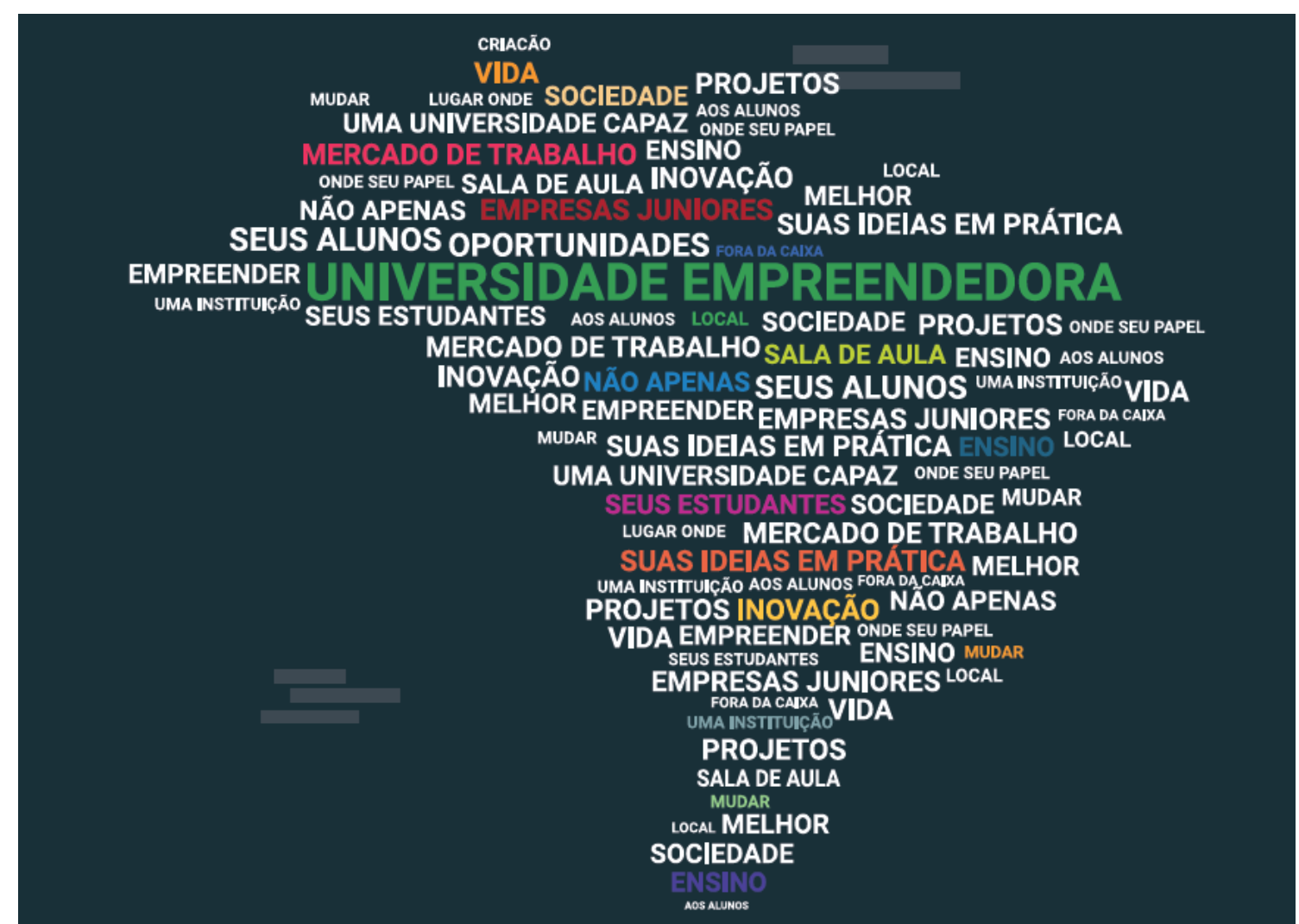

Figura 1 - Universidade empreendedora em palavras - Fonte: Brasil Junior et al, 2016.

Diante da pesquisa, baseada na opinião dos discentes, conforme destacam seus autores, “[...] foi possível realizar um amplo debate que culminou na construção de um conceito com eixos e indicadores que podem medir quantitativamente as características de uma universidade empreendedora" (Brasil Junior et al, 2016:44).

A partir da análise desta imagem, identificam-se palavras que visivelmente ilustram e remetem à nova lógica de funcionamento desse espírito do capitalismo e do seu nexo projetista, conforme defendem Boltanski e Chiapello (2009), tais como: projetos, inovação, mudar, mercado de trabalho, ideias em prática, oportunidade, fora da caixa e empreender.

$\mathrm{Na}$ figura 2 abaixo é possível vislumbrar, assim, os principais eixos - e seus respectivos indicadores - que compõem a universidade empreendedora no Brasil, quais sejam: cultura empreendedora, extensão, inovação, infraestrutura, internacionalização $e$ capital financeiro. 


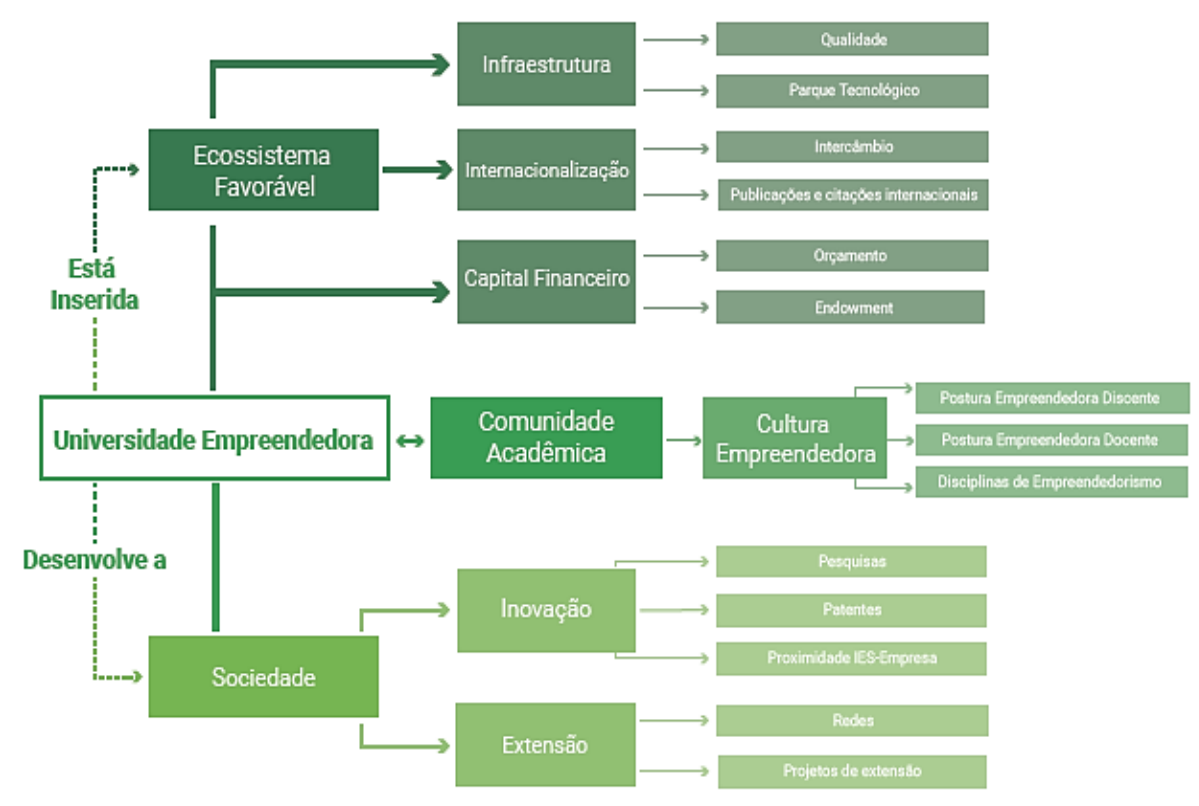

Figura 2 - Universidade empreendedora: eixos e indicadores - Fonte: Brasil Junior et al, 2016.

Conforme destacam os autores do documento, os eixos "cultura", "inovação" e 292 "extensão" medem o que, substancialmente, influencia no empreendedorismo de uma universidade e os eixos "infraestrutura", "internacionalização" e "capital financeiro" medem os meios que facilitam o desenvolvimento do protagonismo acadêmico (Brasil Junior et al, 2016).

No que tange à cultura empreendedora, destacam-se as seguintes características de uma "postura empreendedora": pensamento inovador, coragem para tomar riscos, capacidade de realização, visão para oportunidades, inconformismo com a realidade e disposição para transformá-la, experiência de mercado e apoio a iniciativas empreendedoras (Brasil Junior et $a l, 2016)$. Tais características refletem os valores individuais típicos exaltados no novo espírito do capitalismo, conforme explicitado por Boltanski e Chiapello (2009). Sendo assim, na visão desse documento, as universidades, além de criarem um ambiente propício ao empreendedorismo e à inovação, devem favorecer a formação de uma nova subjetivação nos indivíduos que reflita as características valorizadas nesse novo espírito do capitalismo, ou seja, devem, também, contribuir para os inserirem na lógica dominante do capitalismo.

No eixo da extensão, os seus indicadores são, respectivamente, "redes" e "projetos". Um eixo amplamente voltado para o que se valoriza, efetivamente, no novo espírito do capitalismo. Cabe dizer, nesse sentido, que a universidade empreendedora é uma universidade 
que fortalece a formação de redes em seu âmbito e que, também, atua através do desenvolvimento de projetos ou da lógica projetista da cité por projetos.

A centralidade assumida pela inovação, a partir da criação de um eixo específico, também reflete os impactos do novo espírito do capitalismo no meio acadêmico. Segundo Lopez-Ruiz (2007:70) “[...] inovação, mudança, criatividade, empreendedorismo são hoje palavras de ordem dentro das grandes corporações e também, em boa medida, fora delas". O meio acadêmico, portanto, não fica de fora dessa trama, estando permeado pelos imperativos da inovação permanente e do culto ao novo.

Nesse sentido, a valorização de uma sociedade conexionista também fica evidente na construção deste índice, ao se destacar como indispensáveis, para as universidades empreendedoras, a existência de incubadoras de empresas (eixo inovação) e a aproximação com parques tecnológicos (eixo infraestrutura). Mecanismos estes que favorecem a formação e a ampliação de redes, que estimulem o desenvolvimento de novos projetos, que facilitem a troca de informações, que permitem o crescimento de novos elos e que oferecem oportunidades de empregabilidade.

Já a inclusão de um eixo denominado "internacionalização" revela a necessidade das universidades de se adequarem ao contexto do capitalismo globalizado e conexionista. Assim, o novo espírito do capitalismo se manifesta neste eixo, em específico, por prezar por mais mobilidade (docentes/discentes), por trocas de conhecimentos e experiências, pela aquisição de novas competências, pelo fortalecimento de redes de cooperação, por oportunidades de novos projetos e por novas parcerias.

O estabelecimento do eixo do "capital financeiro" reforça a importância dos investimentos na educação, principalmente em uma época em que existe uma ampla valorização do conhecimento, da qualificação, da aquisição de novas competências e da formação continua para, principalmente, garantir a empregabilidade. É mister ressaltar que no documento, a apresentação de cada um desses eixos é reforçada por "exemplos de sucesso", tanto nacionais quanto internacionais, os quais aparecem como uma forma de conferir legitimidade (justificativa) e facilitar a aceitação e a disseminação de cada um dos pontos propostos.

Os autores do documento expressam sua preocupação, salientando que "a conexão das nossas universidades com o mundo globalizado está longe do ideal” (Brasil Junior et al, 2016:95). Criticam, ainda, o distanciamento das universidades com a realidade do mercado e da sociedade, a falta de postura empreendedora de docentes e discentes, as grades curriculares e os métodos de ensino defasados e o baixo investimento em infraestrutura e recursos 
financeiros. Os autores defendem, também, a conexão e a troca de experiências entre universidades de forma colaborativa e entre os demais setores da sociedade.

Portanto, o que se observa é a construção de um modelo de universidade ajustado e voltado para atender as demandas do atual espírito do capitalismo, sobretudo, no que tange à incorporação de uma lógica empresarial em rede que se vincula à ampla disseminação da lógica de projetos pelos mais diversos âmbitos da esfera social. Ademais, ressalta-se a construção de todo um contexto maior, que engloba diferentes ações as quais começam a orientar as universidades rumo à uma direção mais empresarial, mercadológica e conexionista. Argumenta-se, ainda, que o discurso em torno da construção da universidade empreendedora não se produz por si só, mas resulta de uma complexa teia que envolve diferentes relações, múltiplas ações, determinações legais, práticas, exemplos e orientações que, a todo instante, estão amparadas em diferentes justificativas as quais visam legitimar, naturalizar e tornar esse modelo de universidade passível de ser replicado, como se este fosse um modelo sem ideologia, apolítico e neutro.

\section{Considerações finais}

A partir do que foi exposto, podemos dizer que um grande esforço foi realizado a fim de inserir a educação superior no âmago do novo espírito do capitalismo a partir da construção do documento ora analisado. Dessa forma, tal documento tem a visão de que a educação, como base para as transformações da sociedade e como importante vetor favorável ao seu desenvolvimento, deve adequar-se aos novos imperativos desse novo espírito do capitalismo contemporâneo, bem como a sua lógica projetista, baseada na construção de redes justificações.

Observamos, contudo, que o documento "Universidades Empreendedoras" (Brasil Junior et al, 2016) apresenta argumentos, em seu conteúdo, que refletem os novos imperativos advindos da instauração de um novo espírito do capitalismo, conforme proposto por Boltanski e Chiapello (2009). Ao explicitar que o objetivo central do documento é lançar novos estímulos à educação superior brasileira, este se destaca por idealizar um projeto de universidade específico que deve priorizar, em sua organização, aspectos típicos do novo espírito do capitalismo, tal como o empreendedorismo, a inovatividade, a flexibilidade, os projetos, a interação, a criatividade, entre outros. Destarte, o discurso presente no documento “Universidades Empreendedoras" (Brasil Junior et al, 2016) reflete o novo espírito do 
capitalismo, ao mesmo tempo em que contribui para legitimá-lo, estruturá-lo e justificá-lo, ao estimular a reprodução de práticas a ele relacionadas.

Portanto, o novo espírito do capitalismo não se manifesta somente na estruturação e na defesa de um tipo de universidade específica - a universidade empreendedora -, mas também se encontra presente quando proposto o tipo de comportamento desejável com relação aos docentes e discentes, a saber: a postura empreendedora. Postura esta que muito se assemelha às características individuais dos "grandes" no novo espírito do capitalismo, conforme descrito em Boltanski e Chiapello (2009).

Tendo em vista o que foi até aqui exposto, podemos argumentar que o documento "Universidades Empreendedoras" (Brasil Junior et al, 2016) preza por um discurso que visa inserir as universidades, bem como os indivíduos que as compõem, no contexto do capitalismo atual, defendendo uma reconfiguração e uma atuação em prol das ideologias e dos valores dominantes, priorizando uma educação voltada muito mais para a profissionalização do que para a formação, com grande ênfase na ação individual do homem empreendedor em detrimento do coletivo, com uma maior valorização do conhecimento aplicado e da produção de inovações e patentes, além do fomento da concorrência através do estabelecimento de ranqueamentos e de índices educacionais. Essa é, portanto, a lógica projetista a qual baseia-se o discurso da universidade empreendedora.

Quanto mais as universidades se tornarem empreendedoras, mais se contribuirá para a manutenção do status quo do capitalismo contemporâneo, tanto por adequar as universidades ao seu novo espírito, quanto por manter os indivíduos engajados nele, criando mais redes de justificação e legitimação para seu projeto.

\section{Referências}

BOLTANSKI, Luc; CHIAPELlO, Eve (2009), O novo espírito do capitalismo. São Paulo, Martins Fontes.

BRANDÃO, Helena (2004), Introdução à análise de discurso. Campinas, Editora Unicamp.

BRASIL JUNIOR (2016), O índice de Universidades Empreendedoras. São Paulo, Brasil Junior.

CASAQUI, Vander (2015), "A construção do papel do empreendedor social: mundos possíveis, discurso e o espírito do capitalismo". Galáxia, n. 29, pp. 44-56 [Consult. 31-03-2020]. Disponível em http://www.scielo.br/pdf/gal/n29/1982-2553-gal-29-0044.pdf

CLARK, Burton (1998), Creating entrepreneurial universities: organizational pathways of transformation. Issues in Higher. New York, Elsevier. 
ETZKOWITZ, Henry (1998), "The norms of entrepreneurial science: cognitive effects of the new university-industry linkages". Research Policy, v. 27, n. 8, pp. 823-833. Disponível em https://www.sciencedirect.com/science/article/abs/pii/S0048733398000936 [Consult. 31-03-2020].

ETZKOWITZ, Henry (2002), "Networks of innovation: Science, technology and development in the triple helix era". International Journal of Technology Management \& Sustainable Development, v. 1, n. 1, pp. 7-20 [Consult. 31-03-2020].

Disponível em https://www.ingentaconnect.com/content/intellect/tmsd;jsessionid=1qjr7v6q9i0sb.xic-live-02

ETZKOWITZ, Henry (2003), "Research groups as "quasi-firms": the invention of the entrepreneurial university". Research Policy, n. 32, pp. 109-121 [Consult. 31-03-2020]. Disponível em https://www.sciencedirect.com/science/journal/00487333/32/1

ETZKOWITZ, Henry (2004), "The evolution of the entrepreneurial university". International Journal of Technology and Globalisation, internacional, v. 1, n. 1, pp. 64-77 [Consult. 31-03-2020]. Disponível em https://www.inderscienceonline.com/doi/pdf/10.1504/IJTG.2004.004551

ETZKOWITZ, Henry; WEBSTER, Andrew; GEBHARDT, Christiane; CANTISANO TERRA, Branca R. (2000), "The future of the university and the university of the future: evolution of ivory tower to entrepreneurial paradigm". Research Policy, n. 29, pp. 313-330 [Consult. 31-03-2020]. Disponível em https://www.sciencedirect.com/science/journal/00487333/29/2

ETZKOWITZ, Henry; MELLO José Manoel (2004), "The Rise of a Triple Helix Culture: Innovation in Brazilian Economic and Social Development". International Journal of Technology Management and Sustainable Development, v. 2, n. 3, pp. 159-171 [Consult. 31-03-2020]. Disponível em https://www.ingentaconnect.com/content/intellect/tmsd

GONÇALO, Marcelo (2015), "O novo espírito do capitalismo e as transformações no mundo do trabalho: uma perspectiva crítica". Journal of studies on citizenship and sustainabilit, n. 1, pp. 1-16 [Consult. 31-03-2020].

Disponível em http://civemorum.com.pt/artigos/1/JSCS_1_GMarcelo_pp.199.214.pdf

HARARI, Yuval (2017), Sapiens: uma breve história da humanidade. Porto Alegre, L\&PM.

LÓPEZ-RUIZ, Osvaldo. (2007), Os executivos das transnacionais e o espírito do capitalismo: capital humano e empreendedorismo como valores sociais. Rio de Janeiro, Azougue.

MAIA, Camila; GERMANO, Idilva (2014), "Economia solidária e o novo espírito do capitalismo: uma análise do discurso dos trabalhadores do assentamento coqueirinho". Revista de Psicologia, v. 5, n. 2, pp. 39-52 [Consult. 31-03-2020].

Disponível em http://www.periodicos.ufc.br/psicologiaufc/article/view/1475/1373

MORGADES, Raquel (2016), A Universidade Empreendedora no Novo Modo de Produção da Ciência Contemporânea: Um Estudo de Caso da Universidade Estadual Norte Fluminense Darcy Ribeiro - UENF. 2016. 148 f. Dissertação (Mestrado em Cognição e Linguagem) - Universidade Estadual do Norte Fluminense Darcy Ribeiro, Campos dos Goytacazes.

PETRY, Cleriston (2017), “O novo 'espírito do capitalismo' na reforma curricular do ensino médio da rede pública estadual do RS”. Educ. Foco, v. 22, n. 1, pp. 1-39 [Consult. 31-03-2020]. Disponível em https://periodicos.ufjf.br/index.php/edufoco/article/view/19784/10608 
ROTHAERMEL, Frank.; AGUNG, Shanti.; JIANG, Lin (2007), "University entrepreneurship: a taxonomy of the literature". Industrial and Corporate Change, Oxford, v. 16, n. 4, pp. 1-101 [Consult. 31-03-2020]. Disponível em

https://econpapers.repec.org/article/oupindcch/v_3a16_3ay_3a2007_3ai_3a4_3ap_3a691-791.htm

WEBER, Max (2004), A ética protestante e o "espírito" do capitalismo. São Paulo, Companhia das letras.

\begin{abstract}
The objective of the present study was to analyze, in view of Luc Boltanski' and Éve Chiapello's theory of the new spirit of capitalism, the statement "Entrepreneurial Universities", elaborated in 2016 by the Brazilian Confederation of Junior Enterprises along with other representative institutions. This document addresses the index of the most entrepreneurial universities in Brazil. Thus, the leading question of this paper is: The discourse of the statement "Entrepreneurial Universities" reflects the social logic characteristic of the new spirit of capitalism? Precisely, the study aimed to identify in the statement the assertions, values, arguments and traits which could consign to the ideological apparatus of the new spirit of capitalism. In conclusion, it is possible to say that the discourse of the statement presents arguments that reflect, as well as strengthen, the new demands derived from the establishment of a new spirit of capitalism, as proposed by Boltanski and Chiapello.
\end{abstract}

Keywords: Higher Education; Entrepreneurship; Entrepreneurial University; New Spirit; Capitalism.

\title{
Resumen
}

Este artículo propone analizar, a partir de la teoría del nuevo espíritu del capitalismo de los sociólogos Luc Boltanski y Éve Chiapello, el documento "Universidades Empreendedoras", que fue preparado en 2016 por la Confederación Brasileña de Compañías Junior junto con otras instituciones representativas Este documento resalta el índice de las universidades más emprendedoras de Brasil. Por lo tanto, la pregunta guía de este artículo es: ¿el discurso presente en el documento "Universidades Empreendedoras" refleja la lógica social inspirada en el nuevo espíritu del capitalismo? Más específicamente, se intentó identificar, en el documento propuesto para el análisis, argumentos, valores, justificaciones y características que pueden referirse al aparato ideológico típico del nuevo espíritu del capitalismo. Como conclusión, se puede decir que el discurso presente en el documento analizado presenta argumentos que reflejan, al mismo tiempo que fortalecen, los nuevos imperativos que surgen del establecimiento de un nuevo espíritu de capitalismo, según lo propuesto por Boltanski y Chiapello.

Palabras clave: Educación superior; Emprendimiento; Universidad emprendedora; Nuevo espíritu; Capitalismo. 